\title{
Explotación de sílex rojo en Bahía del Oso Marino (Patagonia Argentina)
}

\author{
Pablo Ambrústolo y Miguel Ángel Zubimendi \\ Recibido 17 de mayo 2018. Aceptado 02 de octubre 2018
}

\begin{abstract}
RESUMEN
En este trabajo se presenta información sobre la explotación prehistórica de una variedad de sílex rojo en función del aprovechamiento de una fuente primaria de aprovisionamiento lítico denominada Punta Norte, emplazada en el litoral atlántico de la provincia de Santa Cruz, Argentina. Las estrategias de utilización de dicha roca, en una escala local, se evalúan con base en el estudio de algunas características de los conjuntos artefactuales líticos registrados en contextos arqueológicos emplazados a distancias variables de la fuente. El hecho de conocer la procedencia del sílex, en este caso representada hasta el momento por una única fuente, permitió realizar una reconstrucción de la trayectoria espacial de la roca a pequeña escala. Las tendencias observadas sugieren que los grupos humanos que ocuparon el mencionado espacio litoral durante el Holoceno medio y tardío realizaron una explotación intensiva del sílex rojo a nivel microlocal, en variados contextos, principalmente en las inmediaciones de la fuente.
\end{abstract}

Palabras clave: Sílex rojo; Fuente primaria; Explotación; Cazadores-recolectores; Patagonia.

\begin{abstract}
RED CHERT EXPOITATION IN OSO MARINO BAY, PATAGONIA ARGENTINA. This paper presents information regarding the prehistoric exploitation of a red chert variety based on the exploitation of one lithic primary procurement source called Punta Norte, located on the Atlantic coast of Santa Cruz province, Argentina. The use strategies of this rock at a local scale are evaluated based on the study of characteristics of lithic artefactual assemblages recorded in archaeological contexts located at varying distances from the source. Knowing the origin of the chert -represented so far by only one source- allowed the spatial trajectory of the rock to be reconstructed on a small scale. The observed trends suggest that the human groups that occupied the coast during the middle and late Holocene carried out an intensive exploitation of red chert at the micro-local level, in various contexts, and mainly in the vicinity of the its source.
\end{abstract}

Keywords: Red chert; Primary source; Exploitation; Hunter-gatherers; Patagonia.

\section{INTRODUCCIÓN}

El estudio de las fuentes de materias primas líticas y de la distribución de los materiales generados en el marco de su explotación constituye una de las vías de entrada para evaluar las estrategias de aprovisionamiento y utilización de esos recursos por parte de los grupos humanos del pasado (Andrefsky 1994, 2009; Franco 2002; Odell 2004; Berón 2006; Barberena et al. 2011; Espinosa et al. 2015, entre otros). Los afloramientos rocosos que

Pablo Ambrústolo. Consejo Nacional de Investigaciones Científicas y Técnicas (CONICET). Facultad de Ciencias Naturales y Museo, Universidad Nacional de La Plata (UNLP). División Arqueología. Museo de Ciencias Naturales de La Plata. Paseo del Bosque s/n. E-mail: pambrustolo@hotmail.com

Miguel Ángel Zubimendi. CONICET. Facultad de Ciencias Naturales y Museo (UNLP). División Arqueología. Museo de Ciencias Naturales de La Plata. Paseo del Bosque s/n. Universidad Nacional de la Patagonia Austral. E-mail: mikelzubimendi@gmail.com 
presentan evidencias de explotación como fuentes de aprovisionamiento podrían ser considerados recursos que poseen un alto valor interpretativo sobre la caracterización de las estrategias tecnológicas y las prácticas sociales que los grupos realizaron en torno a ellos. La importancia de dichos contextos radica en que constituyen el inicio de las secuencias de manufactura lítica y las historias de vida de los artefactos (entre otros, Nelson 1991). En este sentido, uno de los aspectos que reflejan el interés por la detección de las fuentes de materias primas líticas reside en la posibilidad de referenciar los productos de su explotación -en cuanto a las variaciones artefactuales a nivel espacial y temporalcon el origen de dichos materiales. Es decir, como ha sido comprobado en numerosos estudios, las características de las fuentes y el contexto en el que se emplazan pueden determinar, junto con otros factores, el aprovechamiento general del paisaje local y regional en el cual se inscriben las estrategias de obtención de materias primas y su posterior uso y descarte (Bamforth 1986; Nelson 1991; Andrefsky 1994, 2009; Khun 1994; Flegenheimer y Bayón 1999; Escola 2002; Berón 2006; Hiscock 2009; Colombo 2013; Ambrústolo et al. 2015; Bobillo y Hocsman 2015; Espinosa et al. 2015, entre otros).

En función del contexto geológico y geomorfológico en el que se emplazan las fuentes de materias primas líticas, estas pueden clasificarse como primarias (afloramientos, estratos, filones, vesículas) o secundarias (depósitos generados a partir del transporte de material, mediante algún agente geomorfológico, desde su origen hacia espacios cercanos o lejanos) (Luedtke 1979: 745; Nami 1992). En relación con las dimensiones y la superficie que comprenden los asomos y los depósitos de rocas, una diferenciación que consideramos operativa a los fines de realizar estudios espaciales en relación con fuentes que presentan una ubicación conocida es la que plantean Barrientos et al. (2015). Los autores reconocen fuentes caracterizadas como puntuales y fuentes consideradas difusas. Las primeras, definidas a nivel microescalar o local, constituyen contextos de aprovisionamiento primario o secundario, espacialmente restringidos y relativamente aislados de otros similares. Un ejemplo de ello lo constituiría un afloramiento individual de algún tipo de roca. Por otra parte, una fuente difusa comprende un área de abastecimiento que podría ser caracterizada como extensa o muy extensa en el marco de una perspectiva mesoescalar y/o regional. En general, dichos asomos poseen límites poco claros; se trata de depósitos rocosos de origen fluvioglaciar que pueden ser parte de cauces activos o paleocauces, cordones litorales, o simplemente conformar exposiciones de determinadas formaciones geológicas (Barrientos et al. 2015).

La definición de la estructura de recursos líticos (sensu Ericson 1984) de Bahía del Oso Marino (Figura 1) fue caracterizada en trabajos previos. En términos generales, el sector presenta una buena a muy buena disponibilidad de materias primas líticas aptas para la talla (Ambrústolo 2011; Ambrústolo et al. 2015). Sobre la base de descripciones geológicas y geomorfológicas (Giacosa et al. 1998), se realizaron relevamientos en función de la forma en que potencialmente se presentaban las rocas aptas para la talla en el paisaje (Ambrústolo et al. 2015). Se registraron principalmente fuentes secundarias (Luedtke 1979: 745; Nami 1992) que presentan cierta variabilidad litológica debido a que la geología del sector está dominada por depósitos de origen fluvioglaciar (Giacosa et al. 1998). En cuanto a la evaluación de la existencia de las fuentes primarias, se identificó solo la fuente Punta Norte, la cual podría ser caracterizada como una fuente puntual (sensu Barrientos et al. 2015) de sílex rojo que presenta evidencias de explotación. En el marco de dicho registro, en el presente trabajo se pretende evaluar $y$ discutir las estrategias de aprovisionamiento, uso y descarte de dicha materia prima, de disponibilidad inmediata (Bayón y Flegenheimer 2004), en función del estudio integral de algunas características tecnomorfológicas de los conjuntos artefactuales registrados en la fuente y en contextos arqueológicos del sector. Es decir, se pretende caracterizar el paisaje arqueológico respecto del aprovechamiento de sílex rojo en el que coexisten y se superponen espacialmente diferentes escenarios, en cada caso, principalmente compuestos por una fuente de materia prima y un área o espacio de dispersión de materiales provenientes de dicha fuente (Barrientos et al. 2015). El mencionado enfoque se sustenta sobre la idea de que las características temporales y espaciales del registro arqueológico son el resultado de procesos de acumulación que se dan con cierta variabilidad diacrónica, de tasas y escalas. En este sentido, los depósitos arqueológicos son interpretados como palimpsestos con un grado variable de resolución temporal (Catella et al. 2017). Un claro ejemplo de los mencionados escenarios lo constituyen los sitios concheros a cielo abierto identificados en el área, los cuales se emplazan sobre dunas litorales. En términos de Bailey (2007), se trata de palimpsestos acumulativos que presentan 


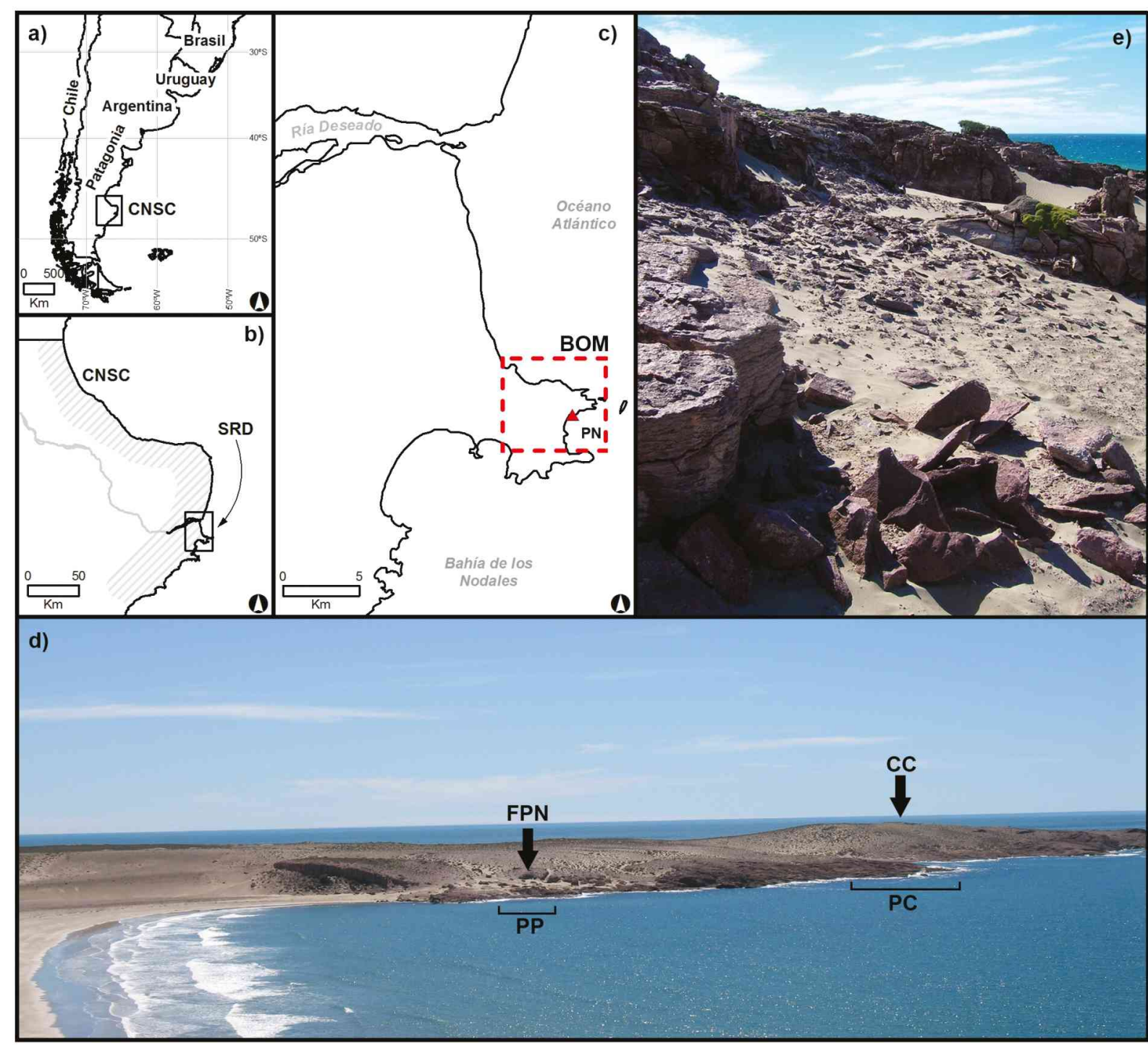

Figura 1. Ubicación y contexto de la fuente Punta Norte. Referencias: a) Costa norte de Santa Cruz (CNSC); b) Sector sur de la ría Deseado (SRD); c) Fuente Punta Norte (FPN) y subsector Bahía del Oso Marino (BOM); d) vista de la punta Norte: FPN = Fuente Punta Norte, PP = Playa de la Piedra, PC = Playa Castillo, y CC = Cima Castillo; e) vista de los afloramientos rocosos donde se encuentra FPN; en primer plano se observa un chenque.

sucesivos episodios de depositación que se superponen y/o mezclan.

\section{La fuente primaria Punta Norte}

En el marco de muestreos y prospecciones realizados en el sur de la ría Deseado, en el noreste de la provincia de Santa Cruz (Ambrústolo 2011; Ambrústolo et al. 2015), se realizaron trabajos de detección de fuentes primarias sobre los afloramientos pertenecientes al Grupo Bahía Laura, los cuales se presentan de forma ubicua en el espacio estudiado (Giacosa et al. 1998). A partir de estos, solo se pudo identificar la denominada fuente Punta Norte (de ahora en adelante, FPN). En función de estudios geomorfológicos realizados en el área (Codignotto et al. 1992, 1993; Pedoja et al. 2011, entre otros), el emplazamiento de la fuente (Figura 1d) sugiere que esta habría estado disponible durante el Holoceno medio y tardío, es decir, no habría sido afectada por la ingresión marina ocurrida hace ca. 5000 años AP. En una zona acotada de un asomo rocoso (Figura 1e), aproximadamente a $15 \mathrm{msnm}$, cubierto parcialmente por sedimentos eólicos sueltos, se registró un espacio de ca. $3 \mathrm{~m}^{2}$ donde se identificaron filones de sílex rojo de muy buena calidad para la talla, los cuales presentan espesores inferiores a $10 \mathrm{~cm}$. Se registraron negativos de lascados, asociados y de forma aislada, y productos de talla en superficie (Figura 2). Dichos rasgos constituyen claras evidencias de la explotación antrópica de la fuente en el pasado (Ambrústolo 2011, 2012).

Como se observa en la Figura 2a, el sector de extracción se presenta conformando una oquedad, 


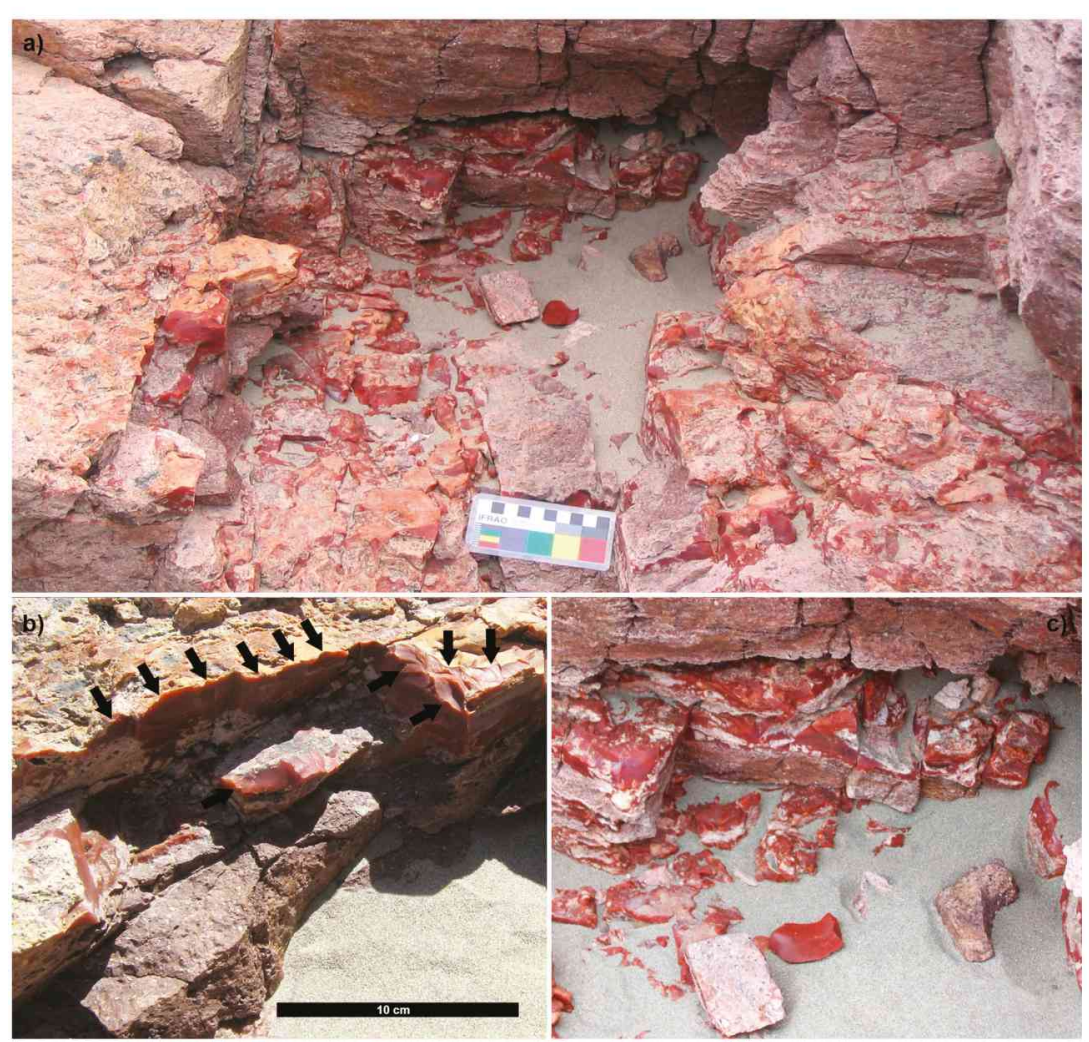

Figura 2. Fuente Punta Norte. Referencias: a) vista general; b) detalle de negativos de lascados aislados y agrupados; c) producto de talla asociado.

Zilio 2013; Hammond 2015; Zilio 2015) y datos resultantes de excavaciones efectuadas en abrigos rocosos y sitios concheros (Ambrústolo et al. 2011; Ambrústolo y Zubimendi 2015; Hammond 2015; Zubimendi y Ambrústolo 2016).

\section{Registro superficial}

El registro lítico en general se presenta conformando sitios arqueológicos a cielo abierto (concheros y talleres) $y$, en menor medida, como hallazgos aislados. Asimismo, los contextos identificados en las ocupaciones de tipo conchero presentan principalmente restos malacológicos y óseos; entre estos últimos se identifican mayoritariamente ejemplares marinos, como pinnípedos y albatros (Zubimendi 2010;

posee una profundidad horizontal de aproximadamente $2 \mathrm{~m}$ respecto del frente del afloramiento y una potencia de unos $70 \mathrm{~cm}$. Es probable que las actividades de aprovisionamiento hayan contribuido a la ampliación del mencionado espacio en función de las tareas de canteo. Las extracciones iniciales se presentan principalmente en serie y lo hacen a partir de plataformas de percusión mínimamente preparadas (Figura 2b); en este sentido, cabe mencionar que se identificaron lascados perpendiculares a la superficie de las plataformas. Dichos rasgos sugieren, junto con el registro de algunos bloques y productos de talla de la roca de caja ignimbrítica que presenta venas y venillas de sílex rojo, la idea de la implementación de tareas de descortezamiento in situ. La extracción posterior de nódulos se habría efectuado mediante percusión directa (Callahan 1979).

\section{CARACTERIZACIÓN DE LOS CONTEXTOS ARQUEOLÓGICOS Y RESULTADOS}

En Bahía del Oso Marino (Figura 1) se han realizado estudios arqueológicos durante los últimos años. Se cuenta con información proveniente de contextos de superficie en el marco de análisis distribucionales (Zubimendi 2010; Zubimendi y
Hammond 2015). En la Figura 3 se pueden observar las ubicaciones y frecuencias relativas de artefactos de sílex rojo provenientes de FPN hallados en contextos superficiales identificados mediante estudios distribucionales efectuados a partir de transectas sistemáticas alineadas y no dirigidas (Zubimendi 2010) y prospecciones asistemáticas (pseudotransectas, sensu Belardi 2003). La metodología de muestreo resultó eficaz debido a las características del paisaje del sector de estudio, el cual es moderadamente uniforme y presenta, en términos generales, una buena a muy buena visibilidad arqueológica (Zubimendi 2010). Los relevamientos se realizaron mediante transectas lineales de $10 \mathrm{~m}$ de ancho $\mathrm{y}$ un largo variable, el cual dependió de las características de las unidades del paisaje analizadas y/o de la logística implementada en el campo. En el marco de este trabajo, las unidades del paisaje se definieron siguiendo los lineamientos propuestos por Zubimendi (2010). Se trata de herramientas que permiten delimitar espacios que presentan características geográficas y geomorfológicas particulares y posibilitan realizar una jerarquización en relación con ciertas expectativas sobre su posible aprovechamiento antrópico. La sectorización de las unidades del paisaje y las geoformas que las componen se realizó sobre la base de estudios geológicos y 


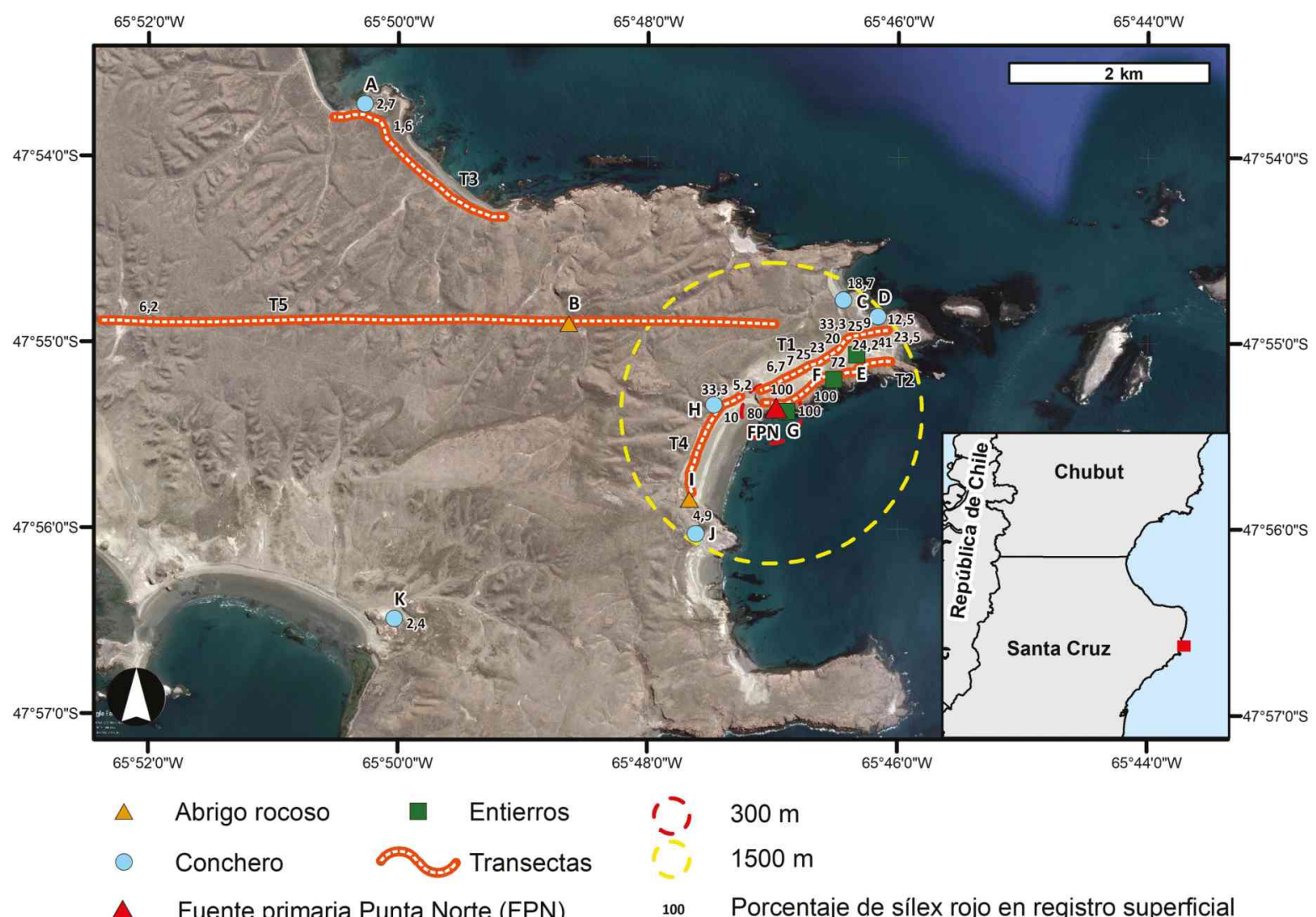

Figura 3. Ubicación de la Fuente Punta Norte (FPN) y contextos arqueológicos mencionados en el texto. Referencias: $\mathrm{A}=$ La Cantera; B = Alero El Oriental; C = La Lobería; D = Cueva del Negro; E = Cima Castillo; F = Playa Castillo; G = Playa de la Piedra; $\mathrm{H}=$ Las Hormigas; $\mathrm{I}=$ Peñón Azopardo 1; $\mathrm{J}=$ Los Albatros; y K = Laureana.

geomorfológicos (Giacosa et al. 1998), interpretación de imágenes satelitales, mapas topográficos y observaciones de campo. En función de ello, con la finalidad de evaluar variaciones distribucionales en escenarios distintos, se definieron cinco unidades del paisaje: Meseta alta, Flanco de Meseta, Lagunas, Cañadones y Costa (Zubimendi 2010). El emplazamiento de las transectas consideradas en este trabajo se relaciona con las unidades presentes en Bahía del Oso Marino, por lo que se efectuaron muestreos en la costa (transectas 1-4) y en el Flanco de Meseta (transecta 5) (Figura 3).

En las inmediaciones de FPN, hasta una distancia aproximada de $300 \mathrm{~m}$ desde la fuente, en la transecta 2 (Figura 3), el sílex rojo se registra en elevadas proporciones (Tabla 1). Se trata de conjuntos poco numerosos y de hallazgos aislados identificados sobre sedimentos arenosos sueltos. Como mencionamos, en función de los procesos de formación del registro arqueológico, los contextos de hallazgo sobre dunas litorales podrían explicar las bajas frecuencias de materiales. En dichos casos es posible que la migración de material y/o el enterramiento, entre otros factores, hayan actuado en detrimento de la integridad de los sitios. En este sentido, cabe mencionar que mediante trabajos experimentales se ha demostrado que, en los médanos litorales, los artefactos más pequeños y delgados pueden ser sepultados con cierta facilidad. Ante dicho escenario, como señala Borrazzo (2006), en los conjuntos líticos de superficie se registrará un doble sesgo: la voladura de microartefactos y el sepultamiento temprano de artefactos pequeños que no puedan ser movilizados por el viento. Ambos procesos, entre otros, podrían generar que la fracción artefactual de tamaños pequeños sea escasa o esté ausente en los conjuntos líticos de superficie en un ambiente de dunas. Ello no deberá ser asumido como resultado de la ausencia de actividades relacionadas, por ejemplo, con estadios finales de talla (Borrazzo 2006; Bailey 2007).

Si se considera el total de piezas reconocidas a menos de $300 \mathrm{~m}$ de la fuente $(\mathbf{n}=8)$, se observa que la mayoría está confeccionada sobre sílex rojo ( $\mathrm{n}=7 ; 87,5 \%$ ) (Tabla 1 ). En todos los casos se trata de productos de talla -lascas secundarias y angulares- de tamaño mediano pequeño (sensu Aschero 1975, 1983). Las características tecnomorfológicas de los artefactos sugieren la puesta en práctica de eventos iniciales de talla, probablemente vinculados con la obtención de formas base. Como se 
observa en la Figura 4a, b y c, ello se evidencia, por ejemplo, en función del elevado registro de piezas $(n=4 ; 57,1 \%)$ que presentan remanente de corteza de la roca de caja ignimbrítica que contiene al sílex rojo de FPN.

En las transectas 1 y 4 y en los sitios emplazados a una distancia de entre 300 y $1500 \mathrm{~m}$ desde FPN (Figura 3), se registran proporciones variables de artefactos de sílex rojo (entre $72,2 \%$ y $5,8 \%$ ) (Figura 5, Tabla 1). Si se tiene en cuenta el conjunto total de artefactos de sílex rojo $(n=110$; $17,1 \%$ ), se observa una significativa disminución de la frecuencia relativa de los estos respecto de los contextos localizados a menos de $300 \mathrm{~m}$ de FPN (Tabla 1). Por otra parte, si bien en el subconjunto predominan los productos de talla $(n=82 ; 74,5 \%)$ de tamaño mediano pequeño (sensu Aschero 1983) -representados principalmente por lascas angulares $y$, en menor medida, secundarias y con dorso-, se registra una mayor variabilidad de clases tipológicas, la cual, entre otros factores, podría estar relacionada con el tamaño de la muestra. En este sentido, cabe mencionar la elevada proporción de artefactos formatizados $(n=16 ; 14,5 \%)$ y núcleos ( $n=12 ; 10,9 \%$ ) (Tabla 1 ). En los estudios de arqueología distribucional, las piezas formatizadas se identificaron mayoritariamente en el tramo final de la transecta $1(n=7$; $43,5 \%$ ), a una distancia aproximada de $1,1 \mathrm{~km}$ respecto de FPN (Tabla 1) (Zubimendi 2010). Se trata de tres raspadores (Figura $4 \mathrm{~d}, \mathrm{f}, \mathrm{g}$ ), dos raederas, una punta destacada (sensu Aschero y Hocsman 2004) y un artefacto con filo denticulado confeccionado sobre un raspador (Figura 4e). En cuanto a los núcleos que se registraron en las transectas 1 y 4 , estos fueron reconocidos a distancias variables de la fuente, en contextos ubicados a ca. $500 \mathrm{~m}$ y a ca. $1 \mathrm{~km}$ (Tabla 1). Son ejemplares poliédricos, de tamaño pequeño, y se encuentran agotados (variedad globulosa, sensu Aschero 1983).

En el rango espacial que abarca entre 1500 y $5100 \mathrm{~m}$ respecto de la FPN, se observa con mayor claridad la tendencia que sugiere el decrecimiento en las frecuencias relativas de sílex rojo en función del aumento en las distancias en relación con la fuente de procedencia; en todos los casos se trata de proporciones inferiores a $6 \%$ (Tabla 1, Figura 5). En promedio, si se consideran los artefactos recuperados en la transecta 3 y en los sitios concheros identificados en el mencionado espacio, las frecuencias de sílex rojo son bajas $(n=71$; $3,2 \%$ ). Sobre las clases tipológicas representadas, se observa un claro predominio de los productos de talla $(n=64 ; 90,4 \%)$-representados principalmente por lascas angulares de tamaño pequeño (sensu Aschero 1983)- respecto de los núcleos poliédricos agotados de tamaño pequeño (variedad globulosa, sensu Aschero 1983) $(n=5 ; 7 \%)$ y los artefactos formatizados ( $\mathrm{n}=2 ; 2,8 \%$ ) (Tabla 1).

Con respecto a los conjuntos líticos procedentes de los sitios concheros emplazados a distancias variables de FPN, cabe mencionar que en todos

\begin{tabular}{|c|c|c|c|c|c|c|c|}
\hline \multirow{2}{*}{ Contexto } & \multirow{2}{*}{\multicolumn{2}{|c|}{$\begin{array}{l}\text { Distancia } \\
\text { FPN }(\mathbf{k m})\end{array}$}} & \multirow{3}{*}{$\frac{\mathbf{N}}{1}$} & \multirow{3}{*}{$\begin{array}{c}\text { Sílex rojo } \\
\mathbf{N}(\%)\end{array}$} & \multicolumn{3}{|c|}{ Clases tipológicas } \\
\hline & & & & & PT & AF & NU \\
\hline \multirow{4}{*}{ Transecta 2} & \multirow{4}{*}{$0,1-0,3$} & 0,10 & & & 1 & - & - \\
\hline & & 0,10 & 5 & $4(80)$ & 4 & - & - \\
\hline & & 0,15 & 1 & $1(100)$ & 1 & - & - \\
\hline & & 0,30 & 1 & $1(100)$ & 1 & - & - \\
\hline \multicolumn{3}{|c|}{ Total N (\%) } & 8 & $7(87,5)$ & $7(100)$ & - & - \\
\hline \multirow{3}{*}{ Transecta 4} & \multirow{17}{*}{$0,3-1,5$} & 0,40 & 193 & $10(5,8)$ & 8 & 2 & - \\
\hline & & 0,40 & 10 & $1(10)$ & - & - & 1 \\
\hline & & 0,45 & 3 & $1(33,3)$ & - & - & 1 \\
\hline \multirow{7}{*}{ Transecta 1} & & 0,50 & 6 & $1(16,6)$ & - & - & 1 \\
\hline & & 0,55 & 58 & $4(6,9)$ & 3 & 1 & - \\
\hline & & 0,65 & 13 & $3(23,1)$ & 3 & - & - \\
\hline & & 0,85 & 4 & $1(25)$ & 1 & - & - \\
\hline & & 0,95 & 46 & $19(41,3)$ & 19 & - & - \\
\hline & & 1,00 & 3 & $1(33,3)$ & 1 & - & - \\
\hline & & 1,00 & 5 & $1(20)$ & 1 & - & - \\
\hline C. Castillo & & 1,00 & 32 & $9(28,1)$ & 6 & 1 & 2 \\
\hline \multirow{3}{*}{ Transecta 1} & & 1,10 & 17 & $4(23,5)$ & 3 & 1 & - \\
\hline & & 1,15 & 8 & $2(25)$ & 1 & - & 1 \\
\hline & & 1,20 & 18 & $13(72,2)$ & 7 & 5 & 1 \\
\hline La Lobería & & 1,30 & 192 & $36(18,7)$ & 26 & 5 & 5 \\
\hline \multirow{2}{*}{ Transecta 1} & & 1,30 & 11 & $1(9,1)$ & - & 1 & - \\
\hline & & 1,40 & 24 & $3(12,5)$ & 3 & - & - \\
\hline \multicolumn{3}{|c|}{$\frac{1}{\text { Total N }(\%)}$} & 643 & $110(17,1)$ & $82(74,5)$ & $16(14,5)$ & $12(10,9)$ \\
\hline Albatros & \multirow{5}{*}{$1,5-7,9$} & 1,70 & 565 & $28(4,9)$ & 26 & - & 2 \\
\hline Laureana & & 4,20 & 587 & $15(2,4)$ & 13 & 1 & 1 \\
\hline Transecta 3 & & 4,80 & 61 & $1(1,6)$ & 1 & - & - \\
\hline La Cantera & & 5,10 & 953 & $26(2,7)$ & 24 & 1 & 1 \\
\hline Transecta 5 & & 6,50 & 16 & $1(6,2)$ & - & - & 1 \\
\hline \multicolumn{3}{|c|}{ Total N (\%) } & 2182 & $70(3,2)$ & $64(91,4)$ & $2(2,8)$ & $5(5,7)$ \\
\hline
\end{tabular}

Nota: FPN: Fuente Punta Norte; N: Frecuencia de artefactos; PT: Productos de talla; AF: Artefactos formatizados; NU: Núcleos.

Tabla 1. Descripción de los contextos de superficie analizados y las tendencias observadas en cuanto a las características tecnomorfológicas de los conjuntos de sílex rojo. 

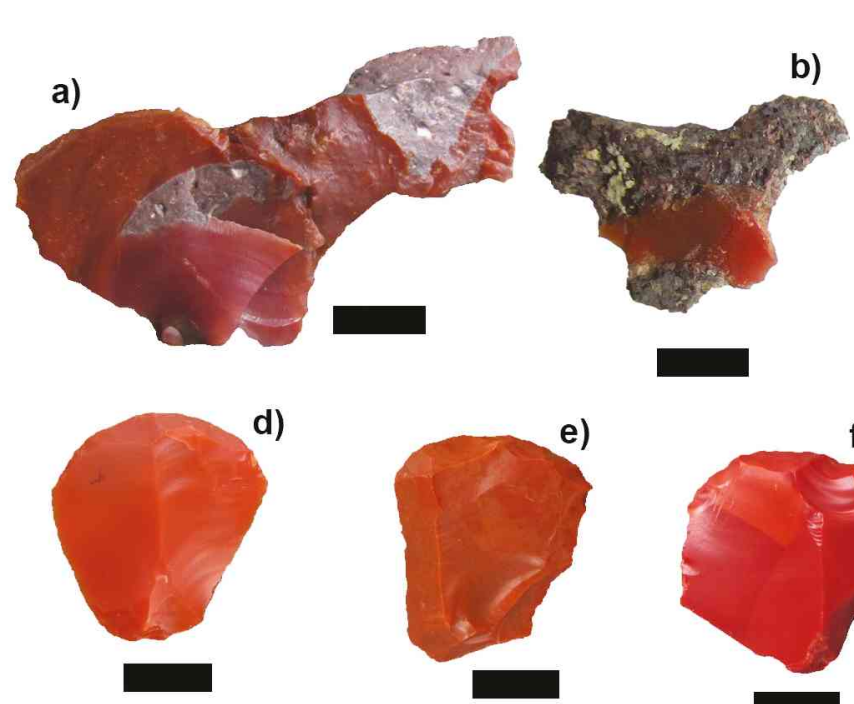

d)

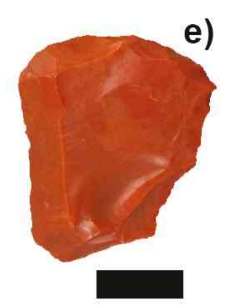

e)

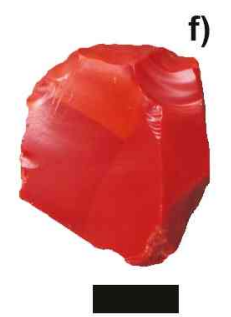

f)

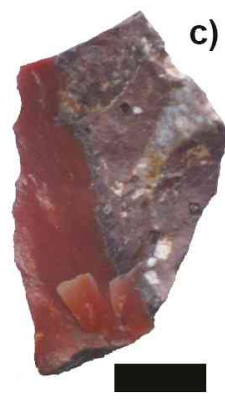

c)

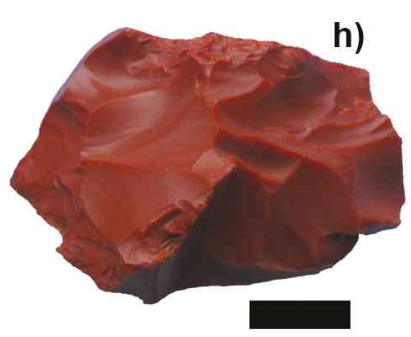

h)
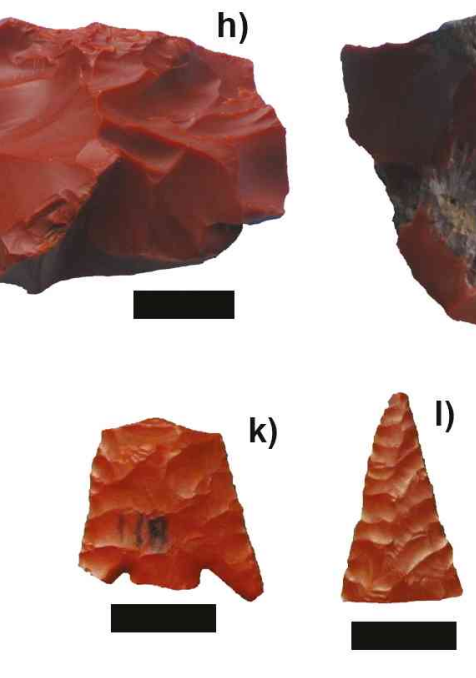

k)

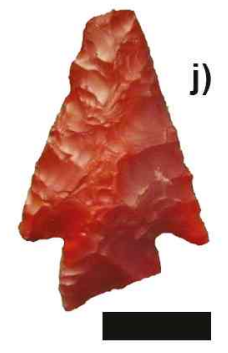

j)

Figura 4. Ejemplos de piezas de sílex rojo procedente de FPN. Las barras negras equivalen a $1 \mathrm{~cm}$. Referencias: lascas con remanente de corteza de la roca de caja: a) Transecta 1; b) Peñón Azopardo 1; c) La Lobería. Raspadores de sílex rojo: d) y g) Transecta 1; e) y f) Transecta 4. Núcleos registrados en el sitio La Lobería: $h$ ) poliédrico no agotado; i) poliédrico no agotado con reserva cortical. Artefactos formatizados del sitio La Lobería: j), k) y l) puntas de proyectil; $m$ ) artefacto bifacial con restos de corteza.

los casos se realizaron transectas intrasitio de recolección superficial (Ambrústolo 2011). La Lobería está ubicado a 1,3 km de la fuente (Figura 3, Tabla 1). En dicho contexto se observa un relativamente elevado registro de piezas confeccionadas sobre sílex rojo $(n=36 ; 18,7 \%$ ) (Tabla 1$)$. Predominan los productos de talla de tamaño pequeño $(n=26$; $72,2 \%$ ) (sensu Aschero 1983), representados principalmente por lascas angulares, con dorso y ejemplares indiferenciados. De los núcleos, el $71 \%(n=5)$ son de sílex rojo proveniente de FPN (Tabla 1). Se trata mayoritariamente de piezas no agotadas y poliédricas (Figura 4h); asimismo, se identificó un ejemplar bipiramidal. En general, presentan reserva cortical constituida por la roca de caja ignimbrítica del afloramiento en el que se encuentra FPN (Figura 4i). El $35,7 \%(n=5)$ de los artefactos formatizados están manufacturados sobre sílex rojo (Tabla 1). El subconjunto comprende tres puntas de proyectil fracturadas (Figura $4 \mathrm{j}, \mathrm{k}$ y I), un raspador frontal y un artefacto bifacial con restos de corteza en ambas caras (Figura $4 \mathrm{~m}$ ). La punta de proyectil de tamaño pequeño y pedúnculo angosto (Figura 4j) está confeccionada sobre una lasca, lo que sugeriría la formatización de artefactos a partir de formas base poco voluminosas. El diseño de dicho instrumento podría ser asignable al descripto por Bird (1938) para los cabezales líticos del Período $V$, asociados con dataciones del Holoceno tardío final de contextos del extremo sur de Patagonia.

Los Albatros es un sitio conchero ubicado a 1,8 $\mathrm{km}$ de FPN (Figura 3). En dicho contexto se identificó un $4,9 \%$ de artefactos confeccionados sobre sílex rojo (Tabla 1). En su mayoría se trata de productos de talla $(n=26 ; 92,8 \%$ )-lascas angulares, de arista y con dorso-. Por otra parte, en el sitio Laureana, ubicado a 4,3 km de FPN (Figura 3), los ejemplares de sílex rojo representan un 2,4\% (Tabla 1). En general, constituyen productos de talla de tamaño pequeño y muy pequeño (sensu Aschero 1983) ( $n=13 ; 86,7 \%)$. Entre ellos se destacan las lascas angulares $y$, en menor medida, los productos de talla indiferenciados y las microlascas. Asimismo, se identificó un núcleo agotado $(6,7 \%)$ y una lasca con retoque $(6,7 \%)$, ambos de tamaño pequeño.

El sitio conchero La Cantera está emplazado a 5,1 km de FPN (Figura 3). A nivel superficial se registró un $2,7 \%(\mathrm{n}=26)$ de artefactos de sílex rojo provenientes de FPN (Tabla 1). Se trata 
principalmente de productos de talla de tamaño muy pequeño (sensu Aschero 1983) ( $\mathrm{n}=24$; $92,3 \%)$, representados en su mayoría por lascas angulares. Asimismo, se registró un núcleo poliédrico $(3,8 \%)$, no agotado, de tamaño pequeño y con un $10 \%$ de reserva cortical. Entre los artefactos formatizados, se identificó una lasca con retoque $(3,8 \%)$ de tamaño pequeño (Tabla 1$)$. Hacia el final de la transecta 5 , a $6,5 \mathrm{~km}$ de FPN, se registró un núcleo tabular $(6,2 \%)$ de tamaño mediano-grande confeccionado sobre sílex rojo (Tabla 1, Figura 3).

En la Tabla 2 se presentan las frecuencias absolutas de las restantes materias primas -diferentes al sílex rojo- que integran los conjuntos artefactuales procedentes de contextos de superficie. En términos generales, se trata de muestras de una importante variabilidad litológica; a excepción de las rocas indeterminadas, se registran al menos doce materias primas. La mayoría de las rocas se presentan disponibles localmente, entre ellas se registran algunas variedades de sílex y tobas silicificadas, vidrio riolítico, ignimbrita, riolita y toba (Ambrústolo 2011; Ambrústolo et al. 2015). Se observa un claro predominio del sílex de variados colores: Transecta $4(n=138 ; 71,5 \%)$, Transecta $1(n=109 ; 66,9 \%)$, Cima Castillo ( $n=15 ; 65,2 \%)$, La Lobería $(n=88$; $56,4 \%)$, Los Albatros $(n=282 ; 52,5 \%)$, Laureana $(n=301 ; 52,6 \%)$, Transecta $3(n=44 ; 73,3 \%)$ y Transecta $5(n=15 ; 93,7 \%)$. Solo en el sitio La Cantera $(n=263 ; 28,4 \%)$ y en la Transecta 2 ( $\mathrm{n}=1 ; 12,5 \%$-la cual es la más cercana a FPN-, el sílex no constituye la materia prima más representada. En La Cantera, el vidrio riolítico es la roca más abundante $(n=479 ; 51,7 \%)$. En las transectas 1 y 4 se observan principalmente -aunque con menores frecuencias respecto del sílex- ingnimbrita, basalto, ópalo (Transecta 4) y toba. En Cima Castillo, La Lobería, Los Albatros y Laureana se registran, asimismo, elevadas proporciones de calcedonia traslúcida $y$, en menor medida, riolita, ignimbrita y obsidiana negra. En la transecta 3 se identifican relativamente altas frecuencias de artefactos confeccionados sobre vidrio riolítico ( $n=11 ; 18,33 \%$ ). Como mencionamos, dicha litología es la más representada -junto con el sílex- en el sitio La Cantera, donde en menor proporción se identifican piezas manufacturadas sobre calcedonia traslúcida $(n=86 ; 9,3 \%)$ y toba $(n=70 ; 7,5 \%)$, entre otras. En cuanto a las clases tipológicas, cabe mencionar que tanto en las transectas como en los sitios se registran mayoritariamente productos de talla de tamaño pequeño $y$, en menor medida, muy pequeño y mediano pequeño (las frecuencias relativas son mayores al $78 \%$ ). En los casos en los que se identificaron núcleos, estos se presentan en bajas frecuencias (inferiores al 4\%) y, en general, son de tamaño pequeño y mediano pequeño. Los artefactos formatizados -principalmente raspadores frontales de tamaño pequeño- se identifican en proporciones variables; a excepción de la transecta 2 , en la que no se observan; en las transectas y/o tramos de transectas más cercanos a FPN (Transecta 4, 1 y Cima Castillo), se registran con mayores proporciones (entre 15 y $21 \%$ ). En las muestras restantes, se identifican con frecuencias relativas que oscilan entre 5,5 y $1,5 \%$.

\section{Registro estratigráfico}

En la Tabla 3 se reseña una descripción de los contextos estratigráficos analizados y las tendencias observadas en las características tecnomorfológicas de los conjuntos de sílex rojo. Se estudiaron las muestras artefactuales de cinco ocupaciones con dataciones asignables al Holoceno medio y tardío. Se trata de los abrigos rocosos Alero El Oriental, Cueva del Negro y Peñón Azopardo 1, y de los sitios concheros Los Albatros y Las Hormigas (Figura 3, Tabla 3).

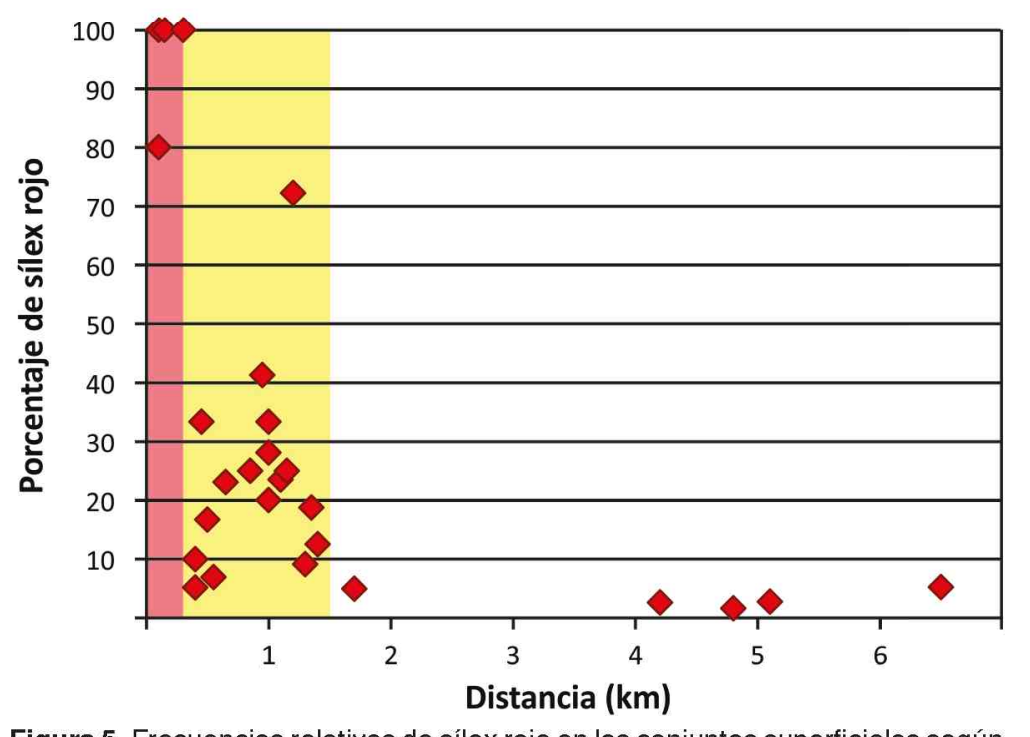

Figura 5. Frecuencias relativas de sílex rojo en los conjuntos superficiales según la distancia a FPN. Nota: en fondo rojo, los primeros $300 \mathrm{~m}$; en fondo amarillo, el rango espacial de $1500 \mathrm{~m}$ respecto de la fuente. 


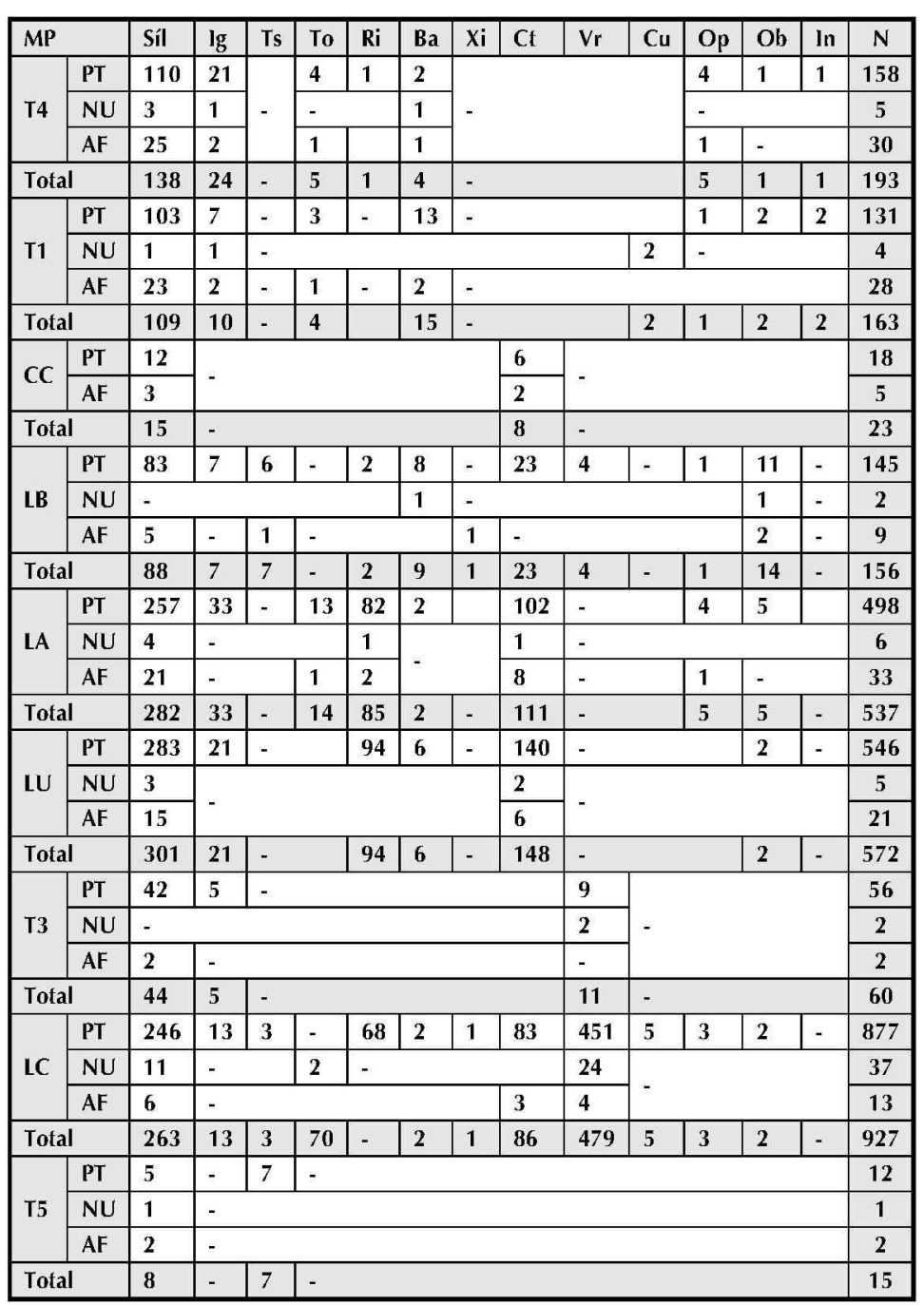

Nota: MP: Materia prima; PT: Productos de talla; NU: Núcleos; AF: Artefactos formatizados: T4: Transecta 4; T1; Transecta 1; CC: Cima Castillo; LB: La Lobería; LA: Los Albatros; LU Laureana; T3: Transecta 3; LC: La Cantera; Síl: Sílex; Ig: Ignimbrita; Ts: Toba silicificada: To: Toba; Ri: Riolita; Ba: Basalto; Xi: Xilopalo; Ct: Calcedonia traslúcida; Vr: Vidrio riolítico; Cu: Cuarcita; Op: Ópalo; Ob: Obsidiana; In: Indeterminada.

Tabla 2. Registro superficial. Frecuencias absolutas de artefactos confeccionados sobre el resto de las materias que conforman los conjuntos líticos.

Al igual que en los contextos de superficie, si bien en términos generales se observa una tendencia decreciente en las proporciones de sílex rojo en función de la distancia de FPN, es interesante resaltar que en el sitio más cercano a la fuente -Las Hormigas, con una datación poscontacto de $370 \pm$ 40 años AP; LP-2504; carbón vegetal (Hammond 2015)-, no se registran artefactos de dicha materia prima (Tabla 3). El contexto más cercano a la fuente, en el que se identifican artefactos de sílex rojo a nivel estratigráfico, es Peñón Azopardo 1. El sitio constituye un abrigo rocoso emplazado a $1,3 \mathrm{~km}$ de la fuente; el $46,1 \%$ de las piezas líticas identificadas están confeccionadas sobre dicha materia prima. Se trata exclusivamente de productos de talla $(n=36)$.
En su mayoría, son piezas indiferenciadas $(n=30 ; 83,3 \%$ ) y, en menor medida, microlascas $(n=6 ; 16,7 \%)$. Cabe mencionar que en algunos artefactos $(n=4 ; 11,1 \%)$ se registró reserva cortical.

Cueva del Negro tiene una cronología de ocupación que abarca un rango temporal que va de ca. 1700 a 1100 años AP (Ambrústolo 2011; Zubimendi et al. 2011). El sitio está emplazado a una distancia similar a la de Peñón Azopardo 1 respecto de FPN; la frecuencia relativa de sílex rojo allí es considerablemente menor $(\mathrm{n}=72 ; 10,4 \%)$. Sin embargo, se observa una mayor variabilidad tipológica en el subconjunto lítico. Principalmente, fueron identificados productos de talla $(n=68 ; 94,4 \%)$, representados por lascas angulares $y$ de arista $(n=49 ; 72 \%)$ de tamaño pequeño y muy pequeño. En menor proporción se registraron productos de talla indiferenciados de tamaño pequeño $(n=19 ; 27,9 \%)$. Asimismo, se reconocieron núcleos amorfos de tamaño pequeño $(n=4 ; 5,5 \%)$, los cuales, al igual que la mayoría de los productos de talla, no presentan restos corticales.

El sitio conchero Los Albatros, con una cronología aproximada de 1100 años AP, está emplazado a ca. 1,8 km de FPN. La proporción de artefactos de sílex rojo registrados a nivel estratigráfico es aún menor que en Cueva del Negro ( $n=2 ; 4,1 \%)$. Se identificaron dos productos de talla (Tabla 3); se trata de una microlasca y una lasca angular de tamaño pequeño. Ninguno de los dos ejemplares posee reserva de corteza.

El sitio Alero El Oriental es el más distante de FPN (ca. 2,1 km). En el componente superior de la ocupación -con una datación de $1530 \pm 60$ años AP; LP 2267; carbón vegetal-, el sílex rojo se registró con una frecuencia relativa de $8,5 \%(n=4)$ (Tabla 3). El subconjunto está conformado por dos microlascas, una lasca de arista de tamaño muy pequeño y un producto de talla indiferenciado. En ningún caso se identificaron ejemplares con restos de corteza. En momentos de exploración inicial del 


\begin{tabular}{|c|c|c|c|c|c|c|c|}
\hline \multirow{2}{*}{ Sitio } & \multirow{2}{*}{\multicolumn{2}{|c|}{$\begin{array}{l}\text { Distancia } \\
\text { FPN }(\mathbf{K m})\end{array}$}} & \multirow{3}{*}{$\begin{array}{c}\mathbf{N} \\
380\end{array}$} & \multirow{3}{*}{$\begin{array}{c}\text { Sílex rojo } \\
\mathrm{N}(\%)\end{array}$} & \multicolumn{3}{|c|}{ Clases artef́actuales $\mathrm{N}(\%)$} \\
\hline & & & & & PT & $\mathrm{AF}$ & NU \\
\hline Las Hormigas & \multirow{3}{*}{$0,3-1,5$} & 0,5 & & & - & - & - \\
\hline Peñón Azopardo 1 & & 1,3 & 78 & $36(46,1)$ & $36(100)$ & - & - \\
\hline Cueva del Negro & & 1,4 & 693 & $72(10,4)$ & $68(94,4)$ & - & $4(5,5)$ \\
\hline Los Albatros: excavación & \multirow{3}{*}{$+1,5$} & 1,8 & 49 & $2(4,1)$ & $2(100)$ & - & - \\
\hline Alero El Oriental: CS & & 2,1 & 47 & $4(8,5)$ & $4(100)$ & - & - \\
\hline Alero El Oriental: CMI & & 2,1 & 476 & $20(4,2)$ & $19(95)$ & - & 1(5) \\
\hline
\end{tabular}

Nota: FPN: Fuente Punta Norte; N: Frecuencia de artefactos; PT: Productos de talla; AF: Artefactos formatizados; NU: Núcleos.

Tabla 3. Descripción de los contextos estratigráficos analizados y las tendencias observadas en cuanto a las características tecnomorfológicas de los conjuntos de sílex rojo.

sector -durante el Holoceno medio $(5150 \pm 80$ años AP; LP-2311; carbón vegetal y $6930 \pm 100$ años AP; LP-2318; carbón vegetal)-, las evidencias observadas en los componentes Medio e Inferior del Alero El Oriental indican que la proporción de sílex rojo $(\mathrm{n}=20 ; 4,2 \%)$ es menor que en momentos tardíos (Tabla 3). En las mencionadas ocupaciones se identificaron principalmente productos de talla $(n=19 ; 95 \%)$, constituidos por lascas angulares de tamaño pequeño y muy pequeño, y microlascas. Solo una lasca angular de tamaño pequeño presenta restos de corteza. Cabe mencionar el registro de un núcleo $(5 \%)$ de tamaño pequeño que se presenta agotado (Tabla 3); dicho rasgo podría explicar la causa probable del descarte de la pieza. y Alero El Oriental -componentes medio/inferior- $(n=268 ; 58,8 \%)$. A diferencia de los conjuntos de superficie, se observan elevadas frecuencias de calcedonia traslúcida, una litología no local o, al menos, no registrada inmediatamente disponible hasta el momento: Peñón Azopardo 1 ( $n=8$; $19 \%)$, Cueva del Negro $(n=133$; $21,4 \%)$, Los Albatros -excavación- $(\mathrm{n}=7 ; 14,9 \%)$, Alero $\mathrm{El}$ Oriental -Componente superior- $(n=13 ; 30,2 \%)$ y Alero El Oriental -componentes medio/inferior$(\mathrm{n}=117 ; 25,6 \%)$. En relación con las clases tipológicas representadas en los conjuntos, es interesante señalar que en todos los casos predominan ampliamente los productos de talla (entre 85 y $100 \%$ ). Los artefactos formatizados se identifican con frecuencias relativas bajas (entre 4 y $9 \%$ ) y los núcleos se registran en muy bajas proporciones (entre 0,2 y $4 \%$, Tabla 4). En general, se trata de artefactos que poseen tamaño muy pequeño y pequeño; en menor medida se identifican piezas mediano-pequeñas.

En la Tabla 4 se expresan las frecuencias absolutas de las restantes materias primas que integran los conjuntos artefactuales procedentes de los contextos estratigráficos. Al igual que lo observado en los conjuntos superficiales, se registra una importante variabilidad litológica y se identifican mayoritariamente rocas de disponibilidad local (variedades de sílex y toba silicificada, ignimbrita, riolita y toba) (Ambrústolo 2011; Ambrústolo et al. 2015). A excepción del sitio Las Hormigas, en el que la calcedonia traslúcida es la roca más abundante ( $\mathrm{n}=307 ; 80,8 \%$ ), el sílex es la materia prima más representada: Peñón Azopardo 1 ( $\mathrm{n}=27 ; 64,3 \%)$, Cueva del Negro ( $\mathrm{n}=265 ; 42,7 \%$ ), Los Albatros -excavación- $(n=35$; $74,5 \%$ ), Alero El Oriental -componente superior- $(n=25 ; 58,1 \%)$

\begin{tabular}{|c|c|c|c|c|c|c|c|c|c|c|c|c|c|c|c|}
\hline \multicolumn{2}{|c|}{ MP } & Sil & Ig & Is & To & $\mathbf{R i}$ & $\mathrm{Ba}$ & $\overline{x i}$ & $\mathrm{Ct}$ & $\mathrm{Vr}$ & $\mathrm{Cu}$ & Op & $\mathrm{Ob}$ & In & $\mathrm{N}$ \\
\hline \multirow{3}{*}{ LH } & PT & 25 & - & 7 & - & 1 & 1 & - & 305 & . & & 31 & - & 1 & 371 \\
\hline & $\mathrm{NU}$ & \multicolumn{10}{|c|}{-} & 3 & \multirow{2}{*}{\multicolumn{2}{|c|}{-}} & 3 \\
\hline & $\mathbf{A F}$ & 4 & & & & & & & 2 & & & - & & & 6 \\
\hline \multicolumn{2}{|c|}{ Total } & 29 & - & 7 & - & 1 & 1 & - & 307 & . & & 33 & - & 1 & 380 \\
\hline PA1 & PI & 27 & 3 & 1 & \multicolumn{4}{|c|}{-} & 8 & & & 3 & \multicolumn{2}{|c|}{-} & 42 \\
\hline \multicolumn{2}{|c|}{ Total } & 27 & 3 & 1 & \multicolumn{4}{|c|}{ - } & 8 & . & & 3 & \multicolumn{2}{|c|}{-} & 42 \\
\hline \multirow{3}{*}{ CDN } & PI & 231 & 29 & 1 & 7 & 154 & 5 & 3 & 124 & 2 & 3 & 1 & 8 & 1 & 569 \\
\hline & NU & 3 & - & 1 & 1 & 1 & & & 1 & \multicolumn{5}{|c|}{-} & 7 \\
\hline & $\mathrm{AF}$ & 31 & \multicolumn{3}{|c|}{-} & 4 & - & 1 & 8 & \multicolumn{2}{|c|}{ - } & 1 & \multicolumn{2}{|c|}{-} & 45 \\
\hline \multicolumn{2}{|c|}{ Total } & 265 & 29 & 2 & 8 & 159 & 5 & 4 & 133 & 2 & 3 & 2 & 8 & 1 & 621 \\
\hline \multirow{3}{*}{ LAE } & $\mathbf{P T}$ & 32 & 4 & - & 1 & \multicolumn{3}{|c|}{-} & 6 & \multicolumn{5}{|c|}{-} & 43 \\
\hline & NU & 1 & & 1 \\
\hline & AF & 2 & \multicolumn{6}{|c|}{. } & 1 & \multirow{2}{*}{\multicolumn{5}{|c|}{ - }} & 3 \\
\hline \multicolumn{2}{|c|}{ Total } & 35 & 4 & - & 1 & \multicolumn{3}{|c|}{ - } & 7 & - & & & & & 47 \\
\hline \multirow{3}{*}{$\begin{array}{c}\text { AEO } \\
\text { CS }\end{array}$} & $\mathbf{P T}$ & 20 & & 1 & - & 1 & & 13 & - & 1 & - & 1 & - & 37 \\
\hline & $\mathrm{NU}$ & 1 & & & & & & & - & & & & 1 & - & 2 \\
\hline & AF & 4 & & & & & & & & & & & & & 4 \\
\hline \multicolumn{2}{|c|}{ Total } & 25 & \multicolumn{2}{|c|}{-} & 1 & & 1 & & 13 & - & 1 & - & 2 & & 43 \\
\hline \multirow{3}{*}{$\begin{array}{l}\text { AEO } \\
\text { CMI }\end{array}$} & PT & 251 & 15 & 2 & 23 & 11 & 3 & - & 116 & 6 & 3 & - & 6 & 1 & 437 \\
\hline & $\mathrm{NU}$ & 1 & & & & & & & - & & & & & & 1 \\
\hline & AF & 16 & . & & 1 & & - & & 1 & & & - & & & 18 \\
\hline To & & 268 & 15 & 2 & 24 & 11 & 3 & - & 117 & 6 & 3 & - & 6 & 1 & 456 \\
\hline
\end{tabular}

Nota: MP: Materia prima; PT: Productos de talla; NU: Núcleos; AF: Artefactos formatizados; LH: Las Hormigas; PA1: Peñón Azopardo 1; CDN: Cueva del Negro; LAE: Los Albatros excavación; AEO CS: Alero El Oriental - componente superior; AEO CMI: Alero El Oriental - componentes medio e inferior; Síl: Sílex; Ig: Ignimbrita; Ts: Toba silicificada; To: Toba; Ri: Riolita; Ba: Basalto; Xi: Xilópalo; Ct: Calcedonia traslúcida; Vr: Vidrio riolítico; Cu: Cuarcita; Op: Ópalo; Ob: Obsidiana; In: Indeterminada.

Tabla 4. Registro estratigráfico. Frecuencias absolutas de artefactos confeccionados sobre el resto de las materias que conforman los conjuntos líticos. 


\section{Estructuras de entierro cercanas a la fuente Punta Norte}

En cercanías de FPN (Figura 1d, e), aproximadamente a $50 \mathrm{~m}$, en las inmediaciones de la denominada Playa de la Piedra (PP), se identificaron nueve estructuras de entierro de tipo chenque con morfología elíptica y anular (Zilio y Zubimendi 2014; Zilio 2015). En Playa Castillo (PC), a ca. $700 \mathrm{~m}$ hacia el este de FPN (Figura $1 \mathrm{~d}$ ), se reconocieron 56 chenques emplazados en la pendiente de un afloramiento rocoso que asoma a escasos metros de la línea de costa actual, en una superficie de solo $7000 \mathrm{~m}^{2}$. Se trata de enterratorios de morfología principalmente anular. En cinco estructuras abiertas por actividades de huaqueo, fue posible reconocer la presencia de restos óseos humanos expuestos en superficie (Zilio 2015). En Cima Castillo (CC, Figura 1d) -el sector más elevado de Playa Castillo, a 1 $\mathrm{km}$ de FPN-, se identificaron dos chenques (Zilio y Zubimendi 2014; Zilio 2015). En asociación espacial directa a dichas estructuras, a nivel superficial, se registró una gran cantidad de restos óseos humanos asociados con material cerámico (59 tiestos) (Trola y Ciampagna 2011) y artefactos líticos (Zilio 2015). El 28,1\% $(n=9)$ de dichas piezas está confeccionado sobre sílex rojo; entre ellos se identificaron principalmente productos de talla $(66,6 \%)$, entre los que se destacan las lascas angulares pequeñas y una hoja mediana; dos núcleos poliédricos pequeños $(22,2 \%)$ y un artefacto formatizado $(11,1 \%)$ representado por un raspador frontal (Tabla 1). Las dataciones radiocarbónicas sobre restos óseos humanos provenientes de dos chenques emplazados en las inmediaciones de Playa Castillo arrojaron cronologías de ca. 750 años AP para dichas estructuras (Zilio 2015). En función de los antecedentes para la CNSC, este tipo de estructuras de entierro tiene una antigüedad de entre 1000 y 300 años AP (Zilio 2015; Zubimendi et al. 2015), rango cronológico que concuerda con los registros para entierros de tipo chenque en la Patagonia continental (Reyes y Méndez 2010; Zilio 2015).

\section{LA EXPLOTACIÓN DE SÍLEX ROJO EN BAHÍA DEL OSO MARINO: DISCUSIÓN Y CONCLUSIONES}

El registro de una fuente primaria de sílex rojo de muy buena calidad para la talla nos permitió realizar un estudio de escala local relativo a las estrategias de obtención y uso de dicha materia prima en Bahía del Oso Marino. Ello posibilitó generar un modelo exploratorio respecto del aprovechamiento espacio-temporal de una litología particular, lo que resultó especialmente interesante dado que se trata, como se expresó, de un sector en el cual las rocas aptas para la talla se encuentran ampliamente disponibles -sobre todo en fuentes secundarias (Ambrústolo 2011; Ambrústolo et al. 2015)- y fueron utilizadas con igual o mayor intensidad que el sílex rojo.

Las tendencias registradas en las variaciones de las frecuencias relativas de los artefactos de sílex rojo provenientes de FPN hallados en diferentes contextos sustentan la idea de que el aprovisionamiento de dicha materia prima se efectuó de forma directa (entre otros, Meltzer 1989). Por otra parte, consideramos que dicho escenario fue factible en un ambiente habitado en condiciones de baja densidad demográfica, baja presión de población sobre los recursos y una amplia disponibilidad de rocas, especialmente de buena a muy buena calidad para la talla. En este sentido, el decrecimiento de las proporciones artefactuales en función de un aumento de la distancia respecto de la fuente de aprovisionamiento (Figura 5), como fuera comprobado a nivel superficial y estratigráfico, es coherente con las expectativas arqueológicas generales inherentes al aprovechamiento de una fuente primaria -que podría definirse como "típica" - de carácter puntual (Renfrew 1977; Meltzer 1989). El mencionado escenario -sumado a la predictibilidad de la disponibilidad de sílex rojo en términos del conocimiento del emplazamiento "puntual" de una fuente de pequeñas dimensiones ubicada en cercanía de las ocupaciones- podría haber estructurado una explotación planificada de dicha fuente (sensu Binford 1979).

Desde el punto de vista diacrónico, las tendencias temporales relativas a la explotación del sílex rojo proveniente de FPN presentan algunas variaciones. En este sentido, las ocupaciones iniciales del sector -las cuales presentan dataciones asignables al Holoceno medio (Alero El Oriental - componentes medio e inferior) (Ambrústolo et al. 2011)- registran frecuencias relativas de sílex rojo $(4,2 \%)$ inferiores a las identificadas en promedio en los contextos con fechados correspondientes al Holoceno tardío $(13,8 \%$, Tabla 3$)$. Sin embargo, en términos generales, la representación de clases tipológicas en los conjuntos líticos de ambos bloques cronológicos es similar; se observa un claro predominio de los productos de talla de tamaño principalmente muy 
pequeño (proporciones mayores a 95\%) sobre los núcleos de tamaño pequeño (entre 3 y $5 \%$ ) (Tabla 3). En ninguno de los dos casos se registran artefactos formatizados. Las frecuencias relativas de las clases tipológicas representadas en ambos escenarios se relacionarían con estrategias de aprovisionamiento directo de sílex rojo en el marco de la explotación de otras materias primas. El hecho de que se reconozca la explotación de la FPN en las ocupaciones iniciales del sector, sumado al registro temprano de evidencias de aprovechamiento de recursos marinos en dichos contextos (Ambrústolo et al. 2011), sustenta la idea del conocimiento $y$ explotación de la fuente desde, al menos, momentos exploratorios. Las diferencias en las frecuencias relativas de sílex rojo entre los contextos del Holoceno medio y los del Holoceno tardío podrían explicarse, entre otras cuestiones, en función de las variaciones en la distancia de FPN respecto de las ocupaciones -el Alero el Oriental está ubicado a $2,1 \mathrm{~km}$ de la fuente- $y / 0$ simplemente en relación con la amplia y variable oferta de rocas disponibles aptas para la talla.

Las evidencias presentadas sobre la explotación del sílex rojo sugieren que el aprovechamiento de dicha materia prima se efectuó principalmente en las inmediaciones de la fuente, en contextos de ocupaciones residenciales -sitios concheros y abrigos rocosos-, talleres y espacios con estructuras de entierro. Cabe mencionar que una explicación al mencionado patrón podría estar relacionada con probables desbalances en la intensidad de los muestreos del espacio litoral en detrimento del territorio interior. En cuanto a los estudios distribucionales, consideramos, sin embargo, como se observa en la Figura 3, que la superficie relevada es similar en las dos grandes unidades del paisaje registradas en Bahía del Oso Marino: Costa y Flanco de Meseta (63.000 $\mathrm{m}^{2}$ y $79.000 \mathrm{~m}^{2}$ respectivamente), por lo que el patrón que indica una mayor proporción de sílex rojo en la costa refleja también las diferencias en la densidad artefactual en todo el espacio.

La explotación inmediata de la fuente habría estado favorecida, entre otros factores, por la muy buena calidad para la talla que presenta la mencionada roca $y$, como mencionamos, por su elevada predictibilidad. La cercanía de la fuente con los loci de ocupación, sin limitaciones geográficas, habría posibilitado un acceso frecuente y sin restricciones a ella, al menos durante el Holoceno tardío. En este sentido, en función de la localización de FPN, es probable que en muchos casos las actividades de aprovisionamiento lítico se realizaran en el marco de estrategias inclusivas o embedded (sensu Binford 1979). Es decir, en determinadas circunstancias, la obtención de sílex rojo se podría haber realizado junto con otras tareas de subsistencia que habrían tenido lugar en los espacios litorales propiamente dichos, como podría ser la adquisición de recursos alimenticios (lobos marinos, moluscos y aves marinas). En este marco, se observa una explotación de sílex rojo a escala local o microlocal, al menos en un radio de ca. $1500 \mathrm{~m}$ desde la fuente de aprovisionamiento. Ello se sustenta en las proporciones y características tecnomorfológicas registradas en los conjuntos líticos emplazados en torno al mencionado rango espacial, donde se registra la trayectoria completa de la roca -entendida como la identificación de todos los estadios involucrados en la secuencia de producción de artefactos-. El hecho de que la disponibilidad de materias primas aptas para la talla sea alta en fuentes secundarias ubicadas en cañadones y mesetas del sector (Ambrústolo 2011; Ambrústolo et al. 2015) constituye otro aspecto que reforzaría la idea de una explotación de sílex rojo a pequeña escala y/o, al menos, como fuera descripto en función de las rocas identificadas en los conjuntos analizados, de forma no exclusiva. Es decir, la amplia oferta lítica del sector, en cuanto a variabilidad litológica y disponibilidad (Ambrústolo et al. 2015), explicaría en parte las características de la demanda en relación con el aprovisionamiento y utilización del sílex rojo en Bahía del Oso Marino. En este sentido, al no tratarse de un recurso crítico, el mencionado escenario no habría demandado la explotación intensiva, en este caso, del sílex de FPN, ni el transporte a grandes distancias de la referida materia prima.

Por otro lado, no debemos olvidar que, como numerosos estudios han resaltado (entre otros, Gould et al. 1971; Flegenheimer y Bayón 1999; Bayón y Flegenheimer 2004; Bloxam 2011; Colombo 2013; Bobillo y Hocsman 2015), las fuentes de materias primas constituyen espacios en los que se reproducen variadas actividades sociales y culturales que trascienden la explotación económica del recurso lítico en particular. En el caso de FPN, ello habría estado facilitado por la cercanía de los sitios residenciales - principalmente concheros-y las estructuras de entierro de tipo chenque.

En suma, el análisis particular de una fuente primaria como Punta Norte y la dispersión de los productos líticos resultantes de su explotación, los cuales fueron identificados en variados contextos a escala local o microlocal-nos ha permitido avanzar 
y discutir los mencionados aspectos en el marco de una visión que integra diferentes líneas de evidencia que hasta el momento se habían enfocado de forma independiente. Consideramos que será necesario evaluar y explorar las tendencias obtenidas a una escala más amplia. En este sentido, en función de los estudios estratigráficos que actualmente estamos realizando en abrigos rocosos no estrictamente litorales, contemplamos la necesidad de incorporar muestras procedentes de contextos datados emplazados en el territorio interior, con el objetivo de seguir evaluando tendencias respecto del aprovisionamiento, transporte y explotación del sílex rojo por parte de los grupos humanos cazadores-recolectores que ocuparon el sector sur de la ría Deseado durante el Holoceno medio y tardío.

\section{Agradecimientos}

A los revisores y editores del trabajo por las valiosas sugerencias y comentarios. A todos aqueIlos que colaboraron en los trabajos de campo y laboratorio. A la Universidad de La Plata, CONICET, FONCYT, Consejo Agrario de la Provincia de Santa Cruz y al Museo Municipal "Mario Brozoski" de la ciudad de Puerto Deseado. Los estudios se realizaron en el marco de los proyectos "Estudios regionales en el río Deseado para definir los rangos de acción de grupos cazadores recolectores costeros en el marco de la ocupación humana del Holoceno de Patagonia" (UNLP-N739) y PICT 2016-0404 "Arqueología de la Cuenca inferior del río Deseado: la ocupación de refugios rocosos en el marco de la explotación de los recursos costeros".

\section{REFERENCIAS CITADAS}

Ambrústolo, P.

2011 Estudio de las estrategias de aprovisionamiento y utilización de los recursos líticos por grupos cazadores recolectores en la Costa Norte de Santa Cruz (Patagonia Argentina). Tesis Doctoral inédita. Facultad de Ciencias Naturales y Museo, Universidad Nacional de La Plata, La Plata.

2012 Explotación de materias primas líticas en el sector sur de la ría Deseado: Análisis de núcleos procedentes de Bahía del Oso Marino (Patagonia Argentina). Intersecciones en Antropología 13: 407-419.

Ambrústolo, P. y M. Zubimendi

2015 New approaches to the study of hunter-gatherers of the north coast of Santa Cruz (Argentina): the use of rock shelters. SAA Archaeological Record 15 (3): 16-20.

Ambrústolo, P., M. A. Zubimendi, L. Ciampagna y V. Trola 2011 Alero El Oriental: Evidencias de las primeras ocupaciones de la Costa Norte de Santa Cruz (Patagonia, Argentina). Revista Werken 14: 9-22.

Ambrústolo, P., M. A. Zubimendi, A. Castro, L. Ciampagna, H. Hammond, L. Zilio y L. Mazzitelli

2015 Fuentes de materias primas líticas en la costa norte de Santa Cruz (Patagonia Argentina): el caso del sur de la ría Deseado. Intersecciones en Antropología. Volumen Especial 2, Materias primas líticas en la Patagonia: 51-60.

Andrefsky, Jr. W.

1994 Raw material availability and the organization of technology. American Antiquity 59: 21-35. doi: $10.2307 / 3085499$

2009 The analysis of stone tool procurement, production, and maintenance. Journal of Archaeological Research 17: 65-103. doi: 10.1007/s10814-008-9026-2

Aschero, C.

1975 Ensayo para una clasificación morfológica de artefactos líticos aplicada a estudios tipológicos comparativos. Informe presentado al CONICET. Buenos Aires.

1983 Ensayo para una clasificación morfológica de artefactos líticos. Revisión del año 1975. Informe presentado al CONICET. Buenos Aires.

Aschero, C. y S. Hocsman

2004 Revisando cuestiones tipológicas en torno a la clasificación de artefactos bifaciales. En Temas de Arqueología. Análisis lítico, editado por M. Ramos, A. Acosta y D. Loponte (eds.), pp. 7-25. Universidad Nacional de Luján, Luján.

Bailey, G.

2007 Time perspectives, palimpsests and the archaeology of time. Journal of Anthropological 26: 198-223. doi: $.1016 / j . j a a .2006 .08 .002$

Bamforth, D. B.

1986 Technological efficiency and tool curation. American Antiquity 51: 38-50. doi: 10.2307/280392

Barberena, R., A. Hajduk, A. F. Gil, G. A. Neme, V. Durán, M. D. Glascock, M. Giesso, K. Borrazzo, M. P. Pompei, M.

L. Salgán, V. Cortegoso, G. Villarosa y A. Rughini 2011 Obsidian in the south-central Andes: geological, geochemical, and archaeological assessment of north Patagonian sources (Argentina). Quaternary International 245 (1): 25-36. doi: 10.1016/j. quaint.2010.09.013 
Barrientos, G., L. Catella y F. Oliva

2015 The spatial structure of lithic landscapes: the late Holocene record of east-central Argentina as a case study. Journal of Archaeological Method and Theory 22 (4): 1151-1192. doi: 10.1007/s10816-014-9220-0

Bayón, C. y N. Flegenheimer

2004 Cambio de planes a través del tiempo para el traslado de rocas en la pampa bonaerense. Estudios Atacameños 28: 59-70. doi: 10.4067/ S0718-10432004002800006

Belardi, J. B.

2003. Paisajes arqueológicos: un estudio comparativo de diferentes ambientes patagónicos. Tesis Doctoral inédita. Facultad de Filosofía y Letras, Universidad Nacional de Buenos Aires, Buenos Aires.

Berón, $M$.

2006 Base regional de recursos minerales en el occidente pampeano. Procedencia y estrategias de aprovisionamiento. Relaciones de la Sociedad Argentina de Antropología XXXI: 47-88.

Binford, L.

1979 Organization and formation processes: looking at curated technologies. Journal of Anthropological Research 35: 255-270. doi: 10.1086/jar.35.3.3629902

Bird, J.

1938 Antiquity and migrations of the early inhabitants of Patagonia. The Geographical Review 28, 250-275. doi: $10.2307 / 210474$.

Bloxam, E.

2011 Ancient quarries in mind: pathways to a more accessible significance. World Archaeology 43 (2):149-166.

Bobillo, F. M. y S. Hocsman

2015 Mucho más que solo aprovisionamiento lítico: Actividades en canteras y prácticas sociales en las fuentes de Pampa Oeste, Quebrada Seca y Punta de la Peña (Antofagasta de la Sierra, Catamarca). Revista del Museo de Antropología 8 (1): 23-44.

Borrazzo, K.

2006 Tafonomía lítica en dunas: una propuesta para el análisis de los artefactos líticos. Intersecciones en Antropología 7: 247-261.

Callahan, E.

1979 The Basics of Biface Knapping in the Eastern Fluted Point Tradition: A Manual for flintknappers and Lithic Analysts. Archaeology of Eastern North America 7 (1): 1-180.
Catella, L., G. Barrientos y F. Oliva

2017 La identificación del uso de fuentes secundarias de materiales líticos asistida por SIG: el Arroyo Chasicó (Argentina) como caso de estudio. Estudios Geológicos 73 (1): e066. doi: 10.3989/egeol.42720.441

Codignotto, J. O., R. Kokot y S. C. Marcomini 1992 Neotectonism and sea level changes in the coastal zone of Argentina. Journal of Coastal Research 8 (1): 125-133.

1993. Desplazamientos verticales y horizontales de la costa argentina en el Holoceno. Revista de la Asociación Geológica Argentina 48 (2): 125-132.

Colombo, $M$.

2013 Los cazadores recolectores pampeanos y sus rocas. La obtención de materias primas líticas vista desde las canteras arqueológicas del centro de Tandilia. Tesis Doctoral inédita. Facultad de Ciencias Naturales y Museo, Universidad Nacional de La Plata, La Plata.

Ericson, J.

1984 Toward the analysis of lithic productions systems. En Prehistoric Quarries and lithic Productions, editado por J. Ericson y B. Purdy, pp. 1-9. Cambridge University Press, Cambridge. doi: 10.1017/ CBO9780511753244.002

Escola, P.

2002 Disponibilidad de recursos líticos y fuentes de aprovisionamiento en un sector de la Puna Meridional. Mundo de Antes 3: 65-86.

Espinosa, S., J. B. Belardi, G. Barrientos, P. Campan y A. Súnico

2015 Disponibilidad, circulación y uso de materias primas líticas en las cuencas de los lagos Tar y San Martín (provincia de Santa Cruz, Argentina). Intersecciones en Antropología. Volumen Especial 2, Materias primas líticas en la Patagonia: 101-111.

Flegenheimer N. y C. Bayón 1999. Abastecimiento de Rocas en Sitios Pampeanos Tempranos: Recolectando Colores. En En los Tres Reinos, Prácticas de recolección en el Cono Sur de América, editado por C. Aschero, A. Korstanje y P. Vuoto, pp. 95-107. Magna, Tucumán.

Franco, N. V.

2002 Estrategias de utilización de recursos líticos en la cuenca superior del río Santa Cruz. Tesis Doctoral inédita. Facultad de Filosofía y Letras, Universidad de Buenos Aires, Buenos Aires. 
Giacosa, R. E., O. Césari y A. Genini 1998 Descripción geológica de la Hoja 4766 III y IV "Puerto Deseado", provincia de Santa Cruz. Boletín Servicio Geológico Minero Argentino (SEGEMAR) 213.

Gould, R.A., D.A. Koster y A. H. Sontz

1971 The lithic assemblage of the western desert aborigines of Australia. American Antiquity 36 (2): 149 169. doi: $10.2307 / 278668$

Hammond, $\mathrm{H}$.

2015 Sitios concheros en la costa norte de Santa Cruz: su estructura arqueológica y variabilidad espacial en cazadores recolectores Patagónicos. Tesis Doctoral inédita. Facultad de Ciencias Naturales y Museo, Universidad Nacional de La Plata, La Plata.

Hiscock, P.

2009 Reduction, recycling, and raw material procurement in Western Arnhem Land, Australia. En Lithic Materials and Paleolithic Societies, editado por B. Adams y B. Blades, pp. 78-93. Wiley-Blackwell, Sussex, doi: 10.1002/9781444311976.ch6

Khun, $S$.

1994 A formal approach to the design and Assembly of mobile toolkits. American Antiquity 59 (3): 426-442. doi: $10.2307 / 282456$

Luedtke, B.

1979 The identification of sources of chert artifacts. American Antiquity 44: 744-757. doi: 10.2307/279116

Meltzer, D.

1989 Was stone exchanged among eastern North American Paleoindians? En Eastern Paleoindian lithic resource use, editado por C. Ellis y J. Lothrop, pp. 1139. Westview Press, Boulder.

Nami, H. G.

$1992 \mathrm{El}$ subsistema tecnológico de la confección de instrumentos líticos y la explotación de los recursos del ambiente: una nueva vía de aproximación. Shincal 2: 33-53.

Nelson, $M$.

1991 The Study of Technological Organization. En Archaeological Method and Theory, editado por $M$. Schiffer, pp. 57-100. University of Arizona Press, Tucson, Arizona.

Odell, G. H.

2004 Lithic Analysis. Kluwer Academic Plenum, Nueva York.

Pedoja, K, V. Regard, L. Husson, J. Martinod, B.

Guillaume, E. Fucks, M. Iglesias y P. Weill

2011. Uplift of quaternary shorelines in eastern
Patagonia: Darwin revisited. Geomorphology 127: 121 142. doi: 10.1016/j.geomorph.2010.08.003

Renfrew, C.

1977 Alternative models for exchange and spatial distribution. En Exchange systems in prehistory, editado por T. K. Earle y J. E. Ericson, pp. 71 90. Academic Press, Nueva York. doi: 10.1016/ B978-0-12-227650-7.50010-9

Reyes, O. y C. Méndez

2010 Precisando la cronología para la inhumación tipo chenque, valle del río Cisne (Aisen, Chile), Patagonia Central. Magallania 38 (2): 127-132. doi: 10.4067/ S0718-22442010000200008

Trola, V. y L. Ciampagna

2011 Primeros análisis de tiestos de cerámica en la Costa Norte de Santa Cruz. En Libro de Resúmenes de las VIII Jornadas de Arqueología de la Patagonia, editado por A. F. Zangrando, R. Barberena, A. Gil y G. Neme, p. 78. Museo de Historia Natural de San Rafael, Mendoza.

Zilio, L.

2015 Prácticas mortuorias en la Costa Norte de Santa Cruz: arqueología de sociedades cazadoras recolectoras en paisajes costeros de la Patagonia argentina. Tesis Doctoral inédita. Facultad de Ciencias Naturales y Museo, Universidad Nacional de La Plata, La Plata.

Zilio, L. y M. A. Zubimendi

2014 Estudio de la distribución de estructuras de entierro en poblaciones cazadoras-recolectoras de la costa norte de Santa Cruz (Patagonia argentina). Revista Española de Antropología Americana 44 (1): 105-126. doi: 10.5209/rev_REAA.2014.v44.n1.47636

Zubimendi, M. A.

2010 Estrategias de uso del espacio por grupos cazadores recolectores en la Costa Norte de Santa Cruz y su interior inmediato. Tesis Doctoral inédita. Facultad de Ciencias Naturales y Museo, Universidad Nacional de La Plata.

Zubimendi, M. A., P. Ambrústolo, M. Beretta, L. Mazzitelli, M. L. Ciampagna, H. Hammond, L. Zilio, M. Plischuk y A. Castro

2011 Sitio Cueva del Negro: Un caso de aprovechamiento intensivo de los recursos marinos en la Costa Norte de Santa Cruz (Patagonia Argentina). Revista de Estudios Marítimos y Sociales 4: 51-62. 


\section{Zubimendi, M. A. y L. Zilio}

2013. Estudios distribucionales en el subsector de las bahías Barco Hundido y del Oso Marino (sector sur de la ría Deseado, costa norte de Santa Cruz). En Tendencias teórico metodológicas y casos de estudio en la arqueología de la Patagonia, editado por A. F. Zangrando, R. Barberena, A. Gil, G. Neme, M. Giardina, L. Luna, C. Otaola, S. Paulides, L. Salgán y A. Tivoli, pp. 545-555. Museo de Historia Natural de San Rafael, Mendoza.
Zubimendi, M. A. y P. Ambrústolo

2016 Estudio comparativo de abrigos rocosos en la costa norte de Santa Cruz (Patagonia). Comechingonia. Revista de Arqueología 20 (1): 253-276. 